\title{
Roles of reactive oxygen species in the spermatogenesis regulation
}

\author{
Giulia Guerriero ${ }^{1,2}{ }^{*}$, Samantha Trocchia ${ }^{1}$, Fagr K. Abdel-Gawad ${ }^{3}$ and Gaetano Ciarcia ${ }^{1,2}$ \\ 'Department of Biology, Università degli Studi di Napoli Federico II, Napoli, Italy \\ ${ }^{2}$ CIRAM, Università degli Studi di Napoli Federico II, Naples, Italy \\ ${ }^{3}$ Department of Water Pollution Research, Centre of Excellence for Advanced Science, National Research Center (NRC), Giza, Egypt
}

Edited by:

Rosaria Meccariello, University of

Naples Parthenope, Italy

Reviewed by:

Rosanna Chianese, Second University

of Naples, Italy

Teresa Chioccarelli, Second University

of Naples, Italy

*Correspondence:

Giulia Guerriero, Department of Biology, Comparative Endocrinology

Lab, Università degli Studi di Napoli

Federico II, Via Mezzocannone, 8,

Naples 80134, Italy

e-mail: giulia.guerriero@unina.it
Spermatogenesis is a complex process of male germ cells proliferation and maturation from diploid spermatogonia, through meiosis, to mature haploid spermatozoa. The process involves dynamic interactions between the developing germ cells and their supporting Sertoli cells. The gonadal tissue, with abundance of highly unsaturated fatty acids, high rates of cell division, and variety of testis enzymes results very vulnerable to the overexpression of reactive oxygen species (ROS). In order to address this risk, testis has developed a sophisticated array of antioxidant systems comprising both enzymes and free radical scavengers. This chapter sets out the major pathways of testis generation, the metabolism of ROS, and highlights the transcriptional regulation by steroid receptors of antioxidant stress enzymes and their functional implications. It also deals with of the advantages of the system biology for an antioxidant under steroid control, the major selenoprotein expressed by germ cells in the testis, the phospholipid hydroperoxide glutathione peroxidase (PHGPx/GPx4) having multiple functions and representing the pivotal link between selenium, sperm quality, and species preservation.

Keywords: spermatogenesis, reactive oxygen species, antioxidants, selenium, healthy reproduction

\section{INTRODUCTION}

Spermatogenesis appears to be a fairly conserved process throughout the vertebrate series. The balance between spermatogonial stem cell self-renewal and differentiation in the adult testis grants cyclic waves of spermatogenesis and potential fertility. These replicative processes imply a highest rate of mitochondrial oxygen consumption and reactive oxygen species (ROS) generation. Enzyme complexes of the respiratory chain of the oxidative phosphorylation, localized on the crests of the mitochondria, as the xanthines, the nicotinamide adenine dinucleotide phosphate (NADPH) oxidase and cytochrome P450, represent a source for a variety of ROS. As known, ROS are free radicals and/or oxygen derivatives that include superoxide anion, hydrogen peroxide, hydroxyl radical, lipid hydroperoxides, peroxyl radicals, and peroxynitrite. They have a dual role in biological systems, both beneficial than harmful depending on their nature and concentration as well as location and length of exposure (1). In this mini-review, we focused our attention on the relevance of ROS role in the spermatogenesis.

\section{REACTIVE OXYGEN SPECIES AND TESTIS MECHANISTIC ANTIOXIDATIVE AND REDOX DEFENSE}

Reactive oxygen species are involved in all cell physiological processes. In testis, they may be beneficial or even indispensable in the complex process of male germ cells' proliferation and maturation, from diploid spermatogonia through meiosis to mature haploid spermatozoa (2). Conversely high doses, and/or inadequate removal of ROS caused by several mechanisms, i.e., ionizing radiation, bioactivation of xenobiotics, inflammatory processes, increased cellular metabolism, activation of oxidases, and oxygenases, can be very dangerous, modifying susceptible molecules including DNA, lipids, and proteins. In addition, testis as tissue, containing large quantities of highly unsaturated fatty acids (particularly 20:4 and 22:6), results vulnerable to ROS attach. The low oxygen tension that characterizes this tissue may be an important component of the self-defense mechanism from free radical-mediated damage during spermatogenesis and Leydig cell steroidogenesis (3); together with an elaborate array of antioxidant enzymes and free radical scavengers ensures that spermatogenic and steroidogenic functions of Leydig cells are not impacted by the overexpression of ROS. In order to have a better understanding of ROS testis' neutralization or limitation by the antioxidant systems, we summarize the major pathways of ROS generation and the mechanistic antioxidative defense in Figure 1. Superoxide radical can be generated by specialized enzymes, such as the xanthine or NADPH oxidases, or as a by-product of cellular metabolism, particularly the mitochondrial electron transport chain, and are converted to hydrogen peroxide by the superoxide dismutase (SOD). Hydrogen peroxide, present as superoxide radical and iron, forms a more reactive form, subsequently converted in lipid peroxide. Lipid peroxide is scavenged to $\mathrm{H}_{2} \mathrm{O}$ by glutathione peroxidase $(\mathrm{GPx})$ or glutathione-S-transferase (GST) (4). The SOD defense by $\mathrm{Cu} / \mathrm{Zn}-\mathrm{SOD}, \mathrm{Fe} / \mathrm{Mn}-\mathrm{SOD}$, and extracellular SOD, is generally achieved by catalase or peroxidases, such as the GPxs, which use reduced glutathione (GSH) as electron donor. Glutathione keeps cells in a reduced state, acting as electron donor for other antioxidative enzymes too, and as a source for the formation of conjugates with some harmful endogenous and xenobiotic compounds, 


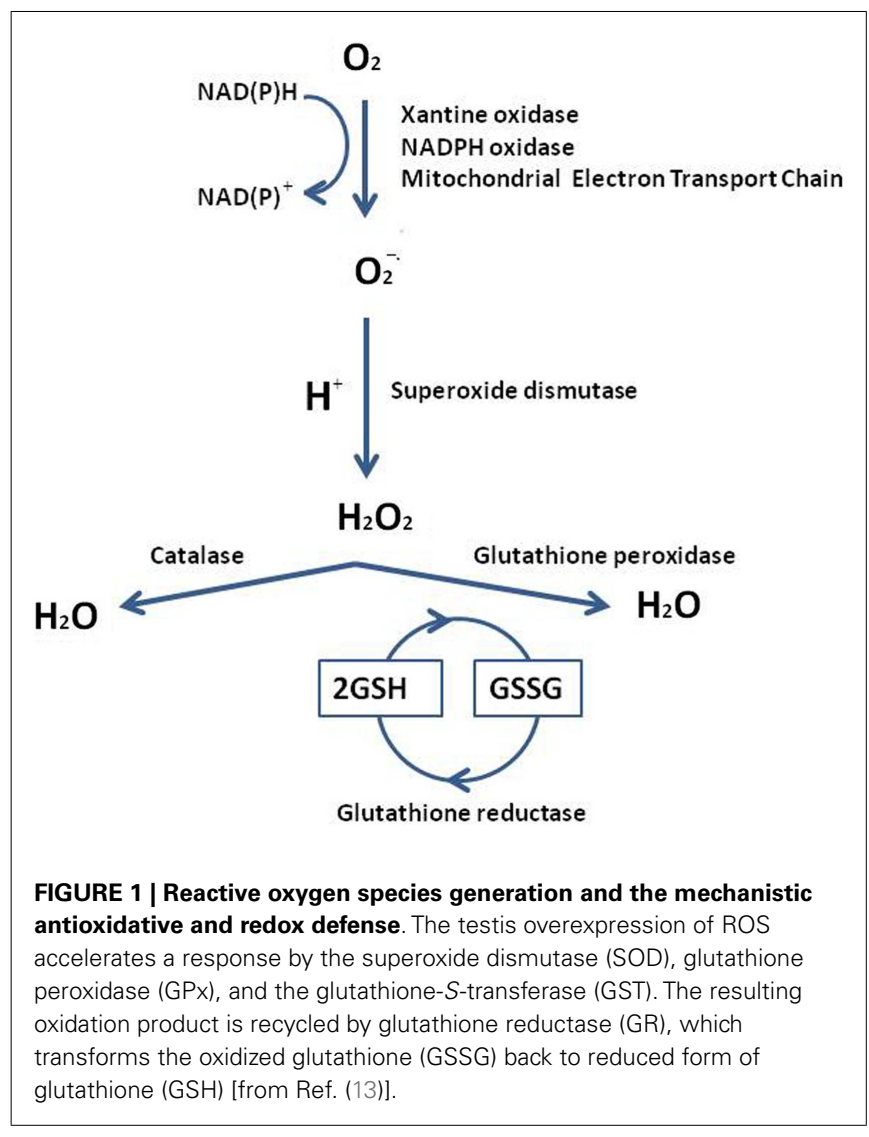

via GST's catalysis. Levels of the reduced glutathione (GSH) are maintained via two ATP-consuming steps, involving c-glutamylcysteine synthetase (cGCS) and glutathione synthetase. The other option constitutes a recycling system involving glutathione reductase (GR): it reduces the oxidized glutathione (GSSG) back to GSH in an NADPH-dependent way. In the interaction of GSH with ROS, GSH serves as an electron donor. The resulting oxidation product, GSSG, is either recycled by GR via electron transfer from NADPH or pumped out of the cells. Thus, GR indirectly participates in the protection of cells against oxidative stress $(5,6)$. In addition to the major ROS processing enzymes, in testis small molecular weight antioxidant substances are present, protecting against oxidative damage. These factors include ions, as zinc and a wide variety of free radical scavengers, vitamins $\mathrm{C}$ or $\mathrm{E}$, melatonin and cytochrome C (7).

\section{REACTIVE OXYGEN SPECIES AND SPERMATOGENESIS TRANSCRIPTIONAL CONTROL}

In vertebrates, the spermatogenesis is controlled by a complex network of endocrine, paracrine, and autocrine signals (8-10) Recent studies summarize different transcription factors, with a regulatory function, who modulate cellular and stage-specific gene expression. In particular, they can be subdivided in general transcription factors; nuclear receptors superfamily; transcription factors involved in testicular functions; testis-specific gene transcription, and transcriptional regulators of cell junction dynamics (11). As reported in Figure 2 in response to the hypothalamic

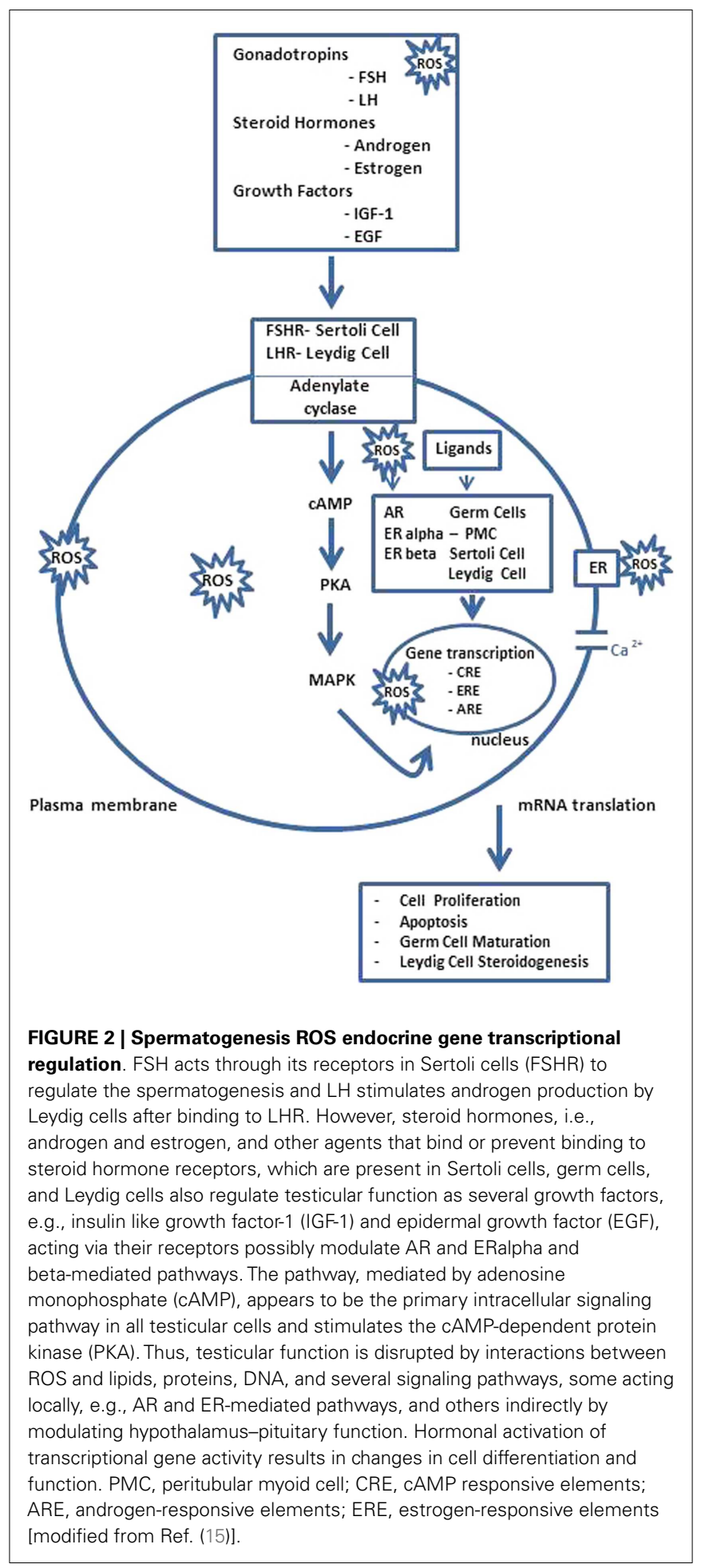

gonadotropin hormone releasing $(\mathrm{GnRH})$, the pituitary gland secretes two hormones, the luteinizing hormone $(\mathrm{LH})$, and the follicle stimulating hormone (FSH), involved in the regulation of spermatogenesis, together with other important transcription factors (3). LH regulates the testosterone secretion by somatic Leydig cells located in the interstitium, between seminiferous 
tubules; FSH acts in Sertoli cells by stimulating signaling, gene expression, and the secretion of peptides and other signaling molecules (12) In Sertoli cells, i.e., the cAMP response element binding protein (CREB) transcription factor, an important transducer of FSH signals. Transcription factors belonging to the CREB family are involved in the regulation of gene expression in response to a number of signaling pathways inducted by ROS overexpression (13). In rat testis, alternatively, the spliced variant CREB mRNAs are spermatogenic, cycle dependent, and expressed during development of the germ and Sertoli cells, indicating that the CREB isoforms may be the major players during spermatogenesis. The transcription factor cAMP response element modulator (CREM) is highly expressed in male germ cells and regulates the expression of several post-meiotic genes, such as the transition proteins and protamines, and it likely is the key regulator of gene expression during spermatogenesis. Targeted disruption of the CREM gene blocks the differentiation program in the first step of spermiogenesis. These findings indicate a crucial role of CREM in post-meiotic germ cells differentiation, linking the action of hormonal stimuli to direct regulation of spermatogenesis genes (14). Now, it is also clear that, not only testicular somatic cells (Leydig and Sertoli cells), but also germ cells express P450arom mRNA, which is translated in a biologically active enzyme involved in the production of estrogens. Therefore, the androgen/estrogen ratio is modified in germ cells, and if testosterone is involved in the regulation of testicular functions, estrogens are also necessary not only in the control of gonadotropins secretion but also in the modulation of the Leydig cells development and steroidogenesis, as well as in the development and/or maintenance of spermatogenesis and spermiogenesis in some mammalian species (15). However, the physiological linkage between different transcription factors and ROS overexpression showed regulation by the estrogen receptor of antioxidative stress enzymes (16), the molecular target genes of these transcription factors at different stages of the seminiferous epithelial cycle are largely unknown and this shall provide an unprecedented opportunity for further investigation in the field.

\section{REACTIVE OXYGEN SPECIES AND SPECIE PRESERVATION}

The maintenance of a high redox potential is a prerequisite to maintain the reproductive systems in a healthy state (17). Reproductive system needs ROS for reproduction, and minimizes the risk caused by ROS using antioxidative systems, such as SOD and GPx. When ROS levels exceed the scavenging capacity of the redox system, under such situations, can repair oxidized and damaged molecules using NADPH as an original electron source. In the context of defense against ROS, selenium as the glutathione (GSH) system plays key functions (18). Selenium has long been known to be necessary for the basal function of many systems of the male reproduction, also (19) is required for the synthesis of testosterone and the formation and development of the sperm (20); its deficiency affects testicular mass with damage to sperm motility, the sperm mid piece, and the shape of the sperm (21). In testis, however, most of the selenium, incorporated into proteins as selenocysteine, is associated to the enzyme phospholipid hydroperoxide GPx, PHGPx/GPx4 (22), member of the GPx named EC 1.11.1.12. PHGPx protects liposomes and biomembranes from peroxidative degradation and exhibits GPx activity on phosphatidylcholine hydroperoxides. It is, infact, able to react with hydroperoxides of fatty acids esterified in the phospholipids $(23,24)$; use protein thiol groups as donor substrates, to protect germ cell, by eliminating oxidative stress and reducing the levels of oxidized molecules. In rodents' testis, PHGPx is localized in the interstitial cells of Leydig, in the nucleus of round spermatids, at the level of the cytoplasm and in the mitochondrial capsule of spermatozoa (25). Here, it is present in three different isoforms: as a cytosolic, mitochondrial, and nuclear protein (26). Functional cis-regulatory elements are identified in the promoter region of nPHGPx (27), whose expression is mediated by the transcription factor CREM-t (28). In spermatids, it is abundantly expressed as active peroxidase and during final maturation, it is transformed into a structural protein enzymatically inactive; it surrounds the helix of mitochondria in the midpiece of the sperm. The nuclear isoform, in particular, is involved in the process of the chromatin condensation, which occurs in the final steps of spermatogenesis and requires the replacement of the majority of histones, with transition proteins and protamines, essential for the stabilization of DNA and condensation of spermatocytes. These changes in location suggest that the nPHGPx can play more than a role in spermatogenesis (29). PHGPx gene expression and activity are hormone dependent processes, and they are influenced by the levels of testosterone during spermatogenesis (30). Steroid hormones do not directly activate transcription and it has been documented that, in vivo, testosterone promote the expression only, as a consequence of the induction of spermatogenesis (30). The study of the mechanisms of gene transcription in testis (31), suggests a crucial role of this antioxidant in male fertility and its usefulness in the screening of a potential threat to the species' continuity $(1,32)$.

\section{CONCLUDING REMARKS}

The overall objective of our mini-review was to highlight the beneficial and detrimental role of ROS that comparatively determine and influence the cyclic waves of spermatogenesis and the species preservation.

\section{ACKNOWLEDGMENTS}

This work was supported by grants from Federico II University of Naples (Italy).

\section{REFERENCES}

1. Aitken RJ, Smith TB, Jobling MS, Baker MA, De Iuliis GN. Oxidative stress and male reproductive health. Asian J Androl (2014) 16(1):31-8. doi:10.4103/1008682X.122203

2. Shi Y, Buffenstein R, Pulliam DA, Van Remmen H. Comparative studies of oxidative stress and mitochondrial function in aging. Integr Comp Biol (2010) 50:869-79. doi:10.1093/icb/icq079

3. Chen C, Ouyang WY, Grigura V, Zhou Q, Carnes K, Lim H, et al. ERM is required for transcriptional control of the spermatogonial stem cell niche. Nature (2005) 436(7053):1030-4. doi:10.1038/nature03894

4. Aitken RJ, Jones KT, Robertson SA. Reactive oxygen species and sperm function - in sickness and in health. J Androl (2012) 33(6):1096-106. doi:10.2164/ jandrol.112.016535

5. Guerriero G, Di Finizio A, Ciarcia G. Oxidative defenses in the seabass, Dicentrarchus labrax. In: Dunn J, Swartz HM editors. Advances in Experimental Medicine and Biology. (Vol. 68), New York: Kluwer Academic/Plenum Plublisher (2003). p. $681-8$.

6. Labuschagne CF, Brenkman AB. Current methods in quantifying ROS and oxidative damage in Caenorhabditis elegans and other model organism of aging. Ageing Res Rev (2013) 12(4):918-30. doi:10.1016/j.arr.2013.09.003 
7. Guerriero G, Ferro R, Russo GL, Ciarcia G. Vitamin E in early stages of sea bass (Dicentrarchus labrax) development. Comp Biochem Physiol A Mol Integr Physiol (2004) 138(4):435-9. doi:10.1016/j.cbpb.2004.06.003

8. Huleihel M, Lunenfeld E. Regulation of spermatogenesis by paracrine/autocrine testicular factors. Asian J Androl (2004) 6:259-68.

9. Cobellis G, Meccariello R, Pierantoni R, Fasano S. Intratesticular signals for progression of germ cell stages in vertebrates. Gen Comp Endocrinol (2003) 134(3):220-8. doi:10.1016/S0016-6480(03)00281-8

10. Pierantoni R, Cobellis G, Meccariello R, Fasano S. Evolutionary aspects of cellular communication in the vertebrate hypothalamo-hypophysio-gonadal axis. Int Rev Cytol (2002) 218:69-141. doi:10.1016/S0074-7696(02)18012-0

11. Lui W-Y, Cheng CY. Transcriptional regulation in spermatogenesis. In: Chang CY editor. Advances in Experimental Medicine and Biology. (Vol. 636), New York: Landes Bioscience and Springer Science + Business Media (2008). p. 115-32.

12. Grimes SR. Testis-specific transcriptional control. Gene (2004) 343:11-22. doi:10.1016/j.gene.2004.08.021

13. Aitken RJ, Roman SD. Antioxidant systems and oxidative stress in the testes. Oxid Med Cell Longev (2008) 1(1):15-24. doi:10.4161/oxim.1.1.6843

14. Ranawat P, Bansal MP. Modulatory effects of selenium on spermatogenesis: involvement of transcription factors CREB and CREM. Am J Biomed Sci (2010) 2(4):329-41. doi:10.5099/aj100400329

15. Akingbemi BT. Estrogen regulation of testicular function. Reprod Biol Endocrinol (2005) 3:51-64. doi:10.1186/1477-7827-3-51

16. Montano MM, Deng H, Liu M, Sun X, Singal R. Transcriptional regulation by the estrogen receptor of antioxidative stress enzymes and its functional implications. Oncogene (2004) 23:2442-53. doi:10.1038/sj.onc.1207358

17. Fujii J, Iuchi Y, Okada F. Fundamental roles of reactive oxygen species and protective mechanisms in the female reproductive system. Reprod Biol Endocrinol (2005) 3:43-53. doi:10.1186/1477-7827-3-43

18. Beckett GJ, Arthur JR. Selenium and endocrine systems. J Endocrinol (2005) 184:455-65. doi:10.1677/joe.1.05971

19. Schreck CB. Stress and fish reproduction: the roles of allostasis and hormesis. Gen Comp Endocrinol (2010) 165:549-56. doi:10.1016/j.ygcen.2009.07.004

20. Behne D, Hofer T, Von Berwordt-Wallrabe R, Elger W. Selenium in the testis of the rat: studies on its regulation and its importance for the organism. J Nutr (1982) 112(9):1682-7.

21. Garrido N, Meseguer M, Carlos Simon C, Pellicer A, Remohi J. Pro-oxidative and anti-oxidative imbalance in human semen and its relation with male fertility. Asian J Androl (2004) 6:59-65.

22. Ursini F, Maiorino M, Valente M, Ferri L, Gregolin C. Purification from pig liver of a protein which protects liposomes and biomembranes from peroxidative degradation and exhibits glutathione peroxidase activity on phosphatidylcholine hydroperoxides. Biochim Biophys Acta (1982) 710: 197-211.

23. Hermesz E, Ferencz A. Identification of two phospholipid hydroperoxide glutathione peroxidase (gpx4) genes in common carp. Comp Biochem Physiol C Toxicol Pharmacol (2009) 150(2):101-6. doi:10.1016/j.cbpc.2009.03.007
24. Saïd L, Banni M, Kerkeni A, Saïd K, Messaoudi I. Influence of combined treatment with zinc and selenium on cadmium induced testicular pathophysiology in rat. Food Cheml Toxicol (2010) 48(10):2759-65. doi:10.1016/j.fct.2010.07.003

25. Nayernia K, Adham IM, Burkhardt-Göttges E, Neesen J, Rieche M, Wolf S, et al. Asthenozoospermia in mice with targeted deletion of the sperm mitochondrionassociated cysteine-rich protein (Smcp) gene. Mol Cell Biol (2002) 22:3046-52. doi:10.1128/MCB.22.9.3046-3052.2002

26. Puglisi R, Tramer F, Carlomagno G, Gandini L, Panfili E, Stefanini M, et al. PHGPx in spermatogenesis: how many functions? Contraception (2005) 72:291-3. doi:10.1016/j.contraception.2005.03.002

27. Borchert A, Wang CC, Ufer C, Schiebel H, Savaskan NE, Kuhn H. The role of phospholipid hydroperoxide glutathione peroxidase isoforms in murine embryogenesis. J Biol Chem (2006) 281(28):19655-64. doi:10.1074/jbc. M601195200

28. Tramer F, Micali F, Sandri G, Bertoni A, Lenzi A, Gandini L, et al. Enzymatic and immunochemical evaluation of phospholipid hydroperoxide glutathione peroxidase (PHGPx) in testes and epididymal spermatozoa of rats of different ages. Int J Androl (2002) 25:72-83. doi:10.1046/j.1365-2605.2002.00327.x

29. Boitani C, Puglisi R. Selenium, a key element in spermatogenesis and male fertility. In: Chang CY editor. Advances in Experimental Medicine and Biology. (Vol. 636), New York: Landes Bioscience and Springer Science + Business Media (2008). p. 65-73.

30. Maiorino M, Wissing JB, Brigelius-Flohe' R, Calabrese F, Roveri A, Steinert P, et al. Testosterone mediates expression of the selenoprotein PHGPx by induction of spermatogenesis and not by direct transcriptional gene activation. FASEB $J$ (1998) 12(13):1359-70.

31. Guthrie HD, Welch GR. Effects of reactive oxygen species on sperm function. Theriogenology (2012) 78(8):1700-8. doi:10.1016/j.theriogenology.2012.05.002

32. Guerriero G, Ciarcia G. Biomarkers of stress and reproduction in fish. In: Reinecke M, Zaccone G, Kapoor BG editors. Fish Endocrinology. (Vol. 2), Enfield, NH: Sci Publ Inc (2006). p. 665-92.

Conflict of Interest Statement: The authors declare that the research was conducted in the absence of any commercial or financial relationships that could be construed as a potential conflict of interest.

Received: 20 March 2014; accepted: 07 April 2014; published online: 22 April 2014. Citation: Guerriero G, Trocchia S, Abdel-Gawad FK and Ciarcia G (2014) Roles of reactive oxygen species in the spermatogenesis regulation. Front. Endocrinol. 5:56. doi: 10.3389/fendo.2014.00056

This article was submitted to Experimental Endocrinology, a section of the journal Frontiers in Endocrinology.

Copyright (C) 2014 Guerriero, Trocchia, Abdel-Gawad and Ciarcia. This is an openaccess article distributed under the terms of the Creative Commons Attribution License (CC BY). The use, distribution or reproduction in other forums is permitted, provided the original author(s) or licensor are credited and that the original publication in this journal is cited, in accordance with accepted academic practice. No use, distribution or reproduction is permitted which does not comply with these terms. 